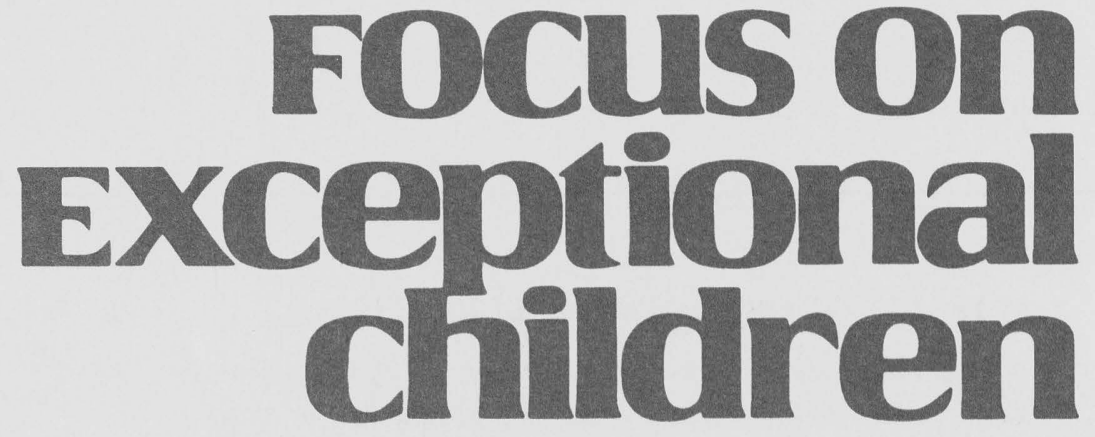

\title{
Courage for the Discouraged: A Psychoeducational Approach to Troubled and Troubling Children
}

\author{
Larry K. Brendtro and Steven Van Bockern
}

The way one defines a problem will determine in substantial measure the strategies that can be used to solve it. -Nicholas Hobbs

In the three decades since the Council for Children with Behavioral Disorders was formed, research about this population has exploded. Professionals working with these challenging children have encountered a cacophony of competing theories and methodology. Too often, proponents for purist viewpoints have been intolerant of other perspectives, berating alternative approaches as unscientific, dehumanizing, or obsolete. Most practitioners, however, have been skeptical of narrow approaches that offer a panacea. When facing a furious student, a single theory offers a slim shield indeed. Now, as our field matures, we finally are moving away from simplistic "one-size-fits-all" mindsets. The term psychoeducational has been used to describe approaches that blend multiple strategies of intervention.

Psychoeducational approaches planfully combine a variety of methods to meet the diverse needs of troubled children. These eclectic models can create a synergy wherein the whole is greater than the parts, but only if the diverse theoretical components are synthesized carefully (Macmillan \& Kavale, 1986). We will review existing psychoeducational approaches and present a new model grounded in practice wisdom and modern developmental theory. At the onset, we must make a distinction between psychoeducation and unstructured eclecticism.

Larry Brendtro is a professor of special education at Augustana College, Sioux Falls, South Dakota, and director of the Black Hills Summer Seminars for Reclaiming Youth. He is co-editor, with Nicholas Long, of the Journal of Emotional and Behavioral Problems. Steve Van Bockern is an associate professor of education at Augustana College and director of the Center for Technology and Learning. He currently directs the River Quest project, an experiential education program funded by the National Science Foundation.

(C) Love Publishing Company, 1994. 


\section{PITFALLS OF GREEN THUMB ECLECTICISM}

In an early study of services for emotionally handicapped children Morse, Cutler, and Fink (1964) found that in many settings no organized philosophy of treatment could be detected. Instead, staffs followed intuitive approaches that observers classified as naturalistic, primitive, or chaotic. Most seemed to use a "green thumb" eclecticism, trying out various procedures without apparent consistency or depth. Their style was neither organized nor proactive but, rather, consisted of spur-of-the-moment responses to individual academic or behavioral problems.

Without a guiding theory to influence selection of interventions, "try anything" eclecticism is like choosing a potluck meal while blindfolded. Among the pitfalls of green thumb eclecticism are:

\section{Focus on
Exceptional
children}

ISSN 0015-511X FOCUS ON EXCEPTIONAL CHILDREN (USPS 203-360) is published monthly except June, July, and August as a service to teachers, special educators, curriculum specialists, administrators, and those concerned with the special education of exceptional children. This publication is annotated and indexed by the ERIC Clearinghouse on Handicapped and Gifted Children for publication in the monthly Current Index to Journals in Education (CIJE) and the quarterly index, Exceptional Children Education Resources (ECER). It is also available in microfilm from Xerox University Microfilms, Ann Arbor, MI. Subscription rates: Individual, $\$ 30$ per year; institutions, $\$ 40$ per year. Copyright (C) 1994, Love Publishing Company. All rights reserved. Reproduction in whole or part without written permission is prohibited. Printed in the United States of America. Second class postage is paid at Denver, Colorado. POSTMASTER: Send address changes to:

Love Publishing Company

Executive and Editorial Office

1777 South Bellaire Street

Denver, Colorado 80222

Telephone (303) 757-2579

Edward L. Meyen

University of Kansas
Glenn A. Vergason Georgia State University

Richard J. Whelan

University of Kansas Medical Center
Stanley F. Love

Publisher
Holly T. Rumpler Senior Editor
1. The flaws of folk psychology. "Doing what comes naturally" with troubled and troublesome youth often entails attacking or avoiding them. These fight/flight responses are highly counterproductive. Harsh punishment easily escalates into hostility, and kindness often is exploited. If a whipping or a dose of love were all that were required, these kids would have been cured long ago.

2. Contradictions in methodology. If techniques drawn from different models are mixed together in potluck fashion, confusion sets in about what to do when theories suggest prescriptions that run counter to one another (Quay \& Werry, 1988). For example, is planfully ignoring angry behavior better, or should one see this anger as a cry for help and communicate with the child?

3. Incompatibility with teamwork. When various team members invent idiosyncratic models of treatment, conflict and chaos reign. Russian youth work pioneer Makarenko (1956) observed that five weak educators inspired by the same principles is a better configuration than 10 good educators all working according to their own opinion.

4. Inconsistency with children. In programs in which adults are confused or inconsistent, anxious students become more agitated and antisocial students more manipulative. The most volatile possible combination is a dysfunctional staff team confronting a cunning and cohesive negative peer group.

Fortunately, we are not confined to naive "green thumb" eclecticism, as a number of thoughtful approaches merge multiple methods. Before presenting our own model, we briefly highlight four major approaches to the reeducation of troubled children.

\section{PERSPECTIVES ON PSYCHOEDUCATION}

In his book, Caring for Troubled Children, Whittaker (1980) identified four principal approaches that have shaped practice in North American programs of reeducation. These all represent different ways of defining emotional and behavioral problems, and they lead to different intervention strategies. Listed in historical sequence, the four models are:

1. Psychodynamic: Children are viewed as "disturbed" because of underlying emotional problems and unmet needs.

2. Behavioral: Children are viewed as "disordered" because of maladaptive patterns of learned behavior. 
3. Sociological: Children are viewed as "maladjusted" because of association with peers who embrace negative values and behavior.

4. Ecological: Various ecosystems in the child's environment are seen as creating conflict and "dis-ease" in children.

Although each model has continued to develop with a separate tradition and literature, these approaches all have become more eclectic over time. Actually, as each model has become more comprehensive, it has been labeled as "psychoeducational" by at least some of its proponents:

1. Psychodynamic psychoeducation places major emphasis on resolving inner conflicts of troubled children. This blending of mental health concepts with education is tied to the early work of a number of outstanding European specialists who emigrated to North America around the time of World War II. Exemplary of this tradition is Fritz Redl (1902-1988), who was trained by August Aichorn and Anna Freud in Austria. Redl and Wineman (1957) worked with what they called highly aggressive youth in Detroit, and co-authored the classic book, The Aggressive Child. Collaborating with William Morse at the University of Michigan Fresh Air Camp for troubled youth, they trained an entire generation of professionals in this model of psychoeducation.

Redl saw emotional disturbance as an exaggeration of feelings common to all individuals. What distinguishes the troubled child was the inability to manage those feelings. Redl also was concerned with behavior, but primarily as a way of understanding the "inner life" of children. His comprehensive approach includes some 20 techniques for "managing surface behavior," and a system for de-escalating crisis situations. He also designed the "life space interview," a counseling strategy used by front line staff (e.g., teachers, youth workers) to transform naturally occurring problems into opportunities for correcting distorted thoughts, feelings, and behaviors. Leading psychoeducational theorists include William Morse (1985) and Nicholas Long, who directs the Institute for Psychoeducational Training in Hagerstown, Maryland.

2. Behavioral psychoeducation uses learning principles to modify the disordered behavior of children. A prominent spokesperson for this version of psychoeducation is Arnold Goldstein of Syracruse University. His data-based belief is that disordered behavior has complex causes and thus is treated best with comprehensive interventions. $\mathrm{He}$ contends that powerful and lasting change requires methods that are both multilevel (directed both at the youth and at the system) and multimodal (combining cognitive, affective, and behavioral interventions).

Goldstein (1988) has combined a variety of behavioral skill training methods into The Prepare Curriculum for teaching prosocial competence. Another widely used example of this merger of methods is Aggression Replacement Training, designed to address the deficits in social skills, anger control, and moral reasoning that characterize aggressive youth (Goldstein \& Glick, 1987).

The eclectic behavioral approach known as the Boys Town Teaching Family Model (Coughlin \& Shanahan, 1991) also qualifies for our definition of psychoeducational. This approach systematically integrates methods including social skills training, relationship building, nonaversive crisis intervention, and structured verbal interventions called "teaching interactions." The Boys Town model is used widely in both residential and public school settings. This model has been subjected to extensive research, and The Boys Town National Training Center in Boys Town, Nebraska, offers professional certification programs (Tierney, Dowd, \& O'Kane, 1993).

3. Sociological psychoeducation utilizes peer groups as a primary agent of change in values and behavior of troubled youth. These programs grew from research showing that delinquent behavior develops through association with peers who support antisocial beliefs and behavior. The impact of peers is strong particularly among youth with weak parental attachments and controls. Unlike traditional group therapy, which treats individuals within a group, the aim of guided group interaction (GGI) is to win over the entire group to prosocial values and behavior, thereby encouraging change in individuals (Empey \& Rabow, 1961).

Harry Vorrath extended the original GGI model into a comprehensive system for reeducation known as PPC, or positive peer culture (Vorrath \& Brendtro, 1985). Peer group models are used most widely in residential treatment (Brendtro \& Wasmund, 1989) and alternative schools and classes for troubled youth (Carducci \& Carducci, 1984; Garner, 1982). PPC also has been proposed as an alternative approach to school discipline (Duke \& Meckel, 1984). Positive peer culture groups identify problems and develop strategies to solve them. The goal is to create a prosocial 
ethos by making caring fashionable, demanding greatness instead of obedience, and challenging youth to assume reșponsibility for their lives. Brendtro and Ness (1983) described a "psychoeducational" approach using peer group strategies with other methods, which has been developed at the Starr Commonwealth Schools for troubled youth in Michigan and Ohio. The National Association of Peer Group Agencies provides research and training on this treatment model (Kern \& Quigley, 1994).

4. Ecological psychoeducation has been the most actively eclectic approach, borrowing freely from the more traditional models. The leading author of this approach was Nicholas Hobbs (1918-1983) who created the Re-ED model at Vanderbilt University. (Re-ED is an acronym for Reeducation for Emotionally Disturbed Children.) The most recent model to develop, Re-ED borrows generously from each of the foregoing models and is described as both ecological and psychoeducational (Lewis \& Lewis, 1989). Hobbs was influenced strongly by European and FrenchCanadian psychoeducation, and he blended education, child care, and treatment into the role of "teacher-counselor."

A past president of the American Psychological Association, Hobbs was a powerful advocate for focusing on strength, health, and joy, rather than deviance and pathology. In The Troubled and Troubling Child, Hobbs (1982) argued that most emotional disturbance is not a symptom of individual pathology but, rather, a sign of malfunctioning human ecosystems. Re-ED professionals strive to develop competence in restorative relationships, working in close liaison with families and communities (Lewis \& Lewis, 1989). The American Re-ED Association, a nationwide network of residential and school-based Re-ED programs, has grown from this ecological tradition. The ReED philosophy now is being applied to the challenging problems of urban schools in settings such as the Positive Education Program in Cleveland, Ohio (Cantrell, 1992).

Cross-fertilization has increased among all of these theories, albeit much of it random, as practitioners intuitively tinker with once pure models. Today, we find behaviorists advocating relationship building, psychodynamic programs using reinforcement concepts, and nearly universal recognition of the importance of group and ecological dynamics. In the face of this intermingling of theories, traditional concepts such as "behavioral" and "psychodynamic" no longer convey a clear meaning at the level of practice.

\section{THE SEARCH FOR A UNIFYING THEME}

A rich array of specialized methods now is available for treating troubled children and youth. What has been missing is a conceptual framework to bind together these separate components into a coherent system. As Yochanan Wozner (1985) of Israel observed, a "powerful reclaiming environment" for troubled youth requires a "unifying theme." This is a shared set of beliefs about program goals that gives consistency and cohesiveness to elements of the program. A unifying theme is essential to mold a common consensus among staff and youth about program mission.

We now propose a unifying theme for psychoeducation that grows from "empowerment" philosophy and psychology. This "new" paradigm challenges the deviance and deficit model that is common in many approaches to troubled children. Our model seeks to address the question, "What do all successful approaches have in common?"

In visiting an air show, one might see machines as diverse as biplanes and bombers, but each is able to fly only because it has been designed to the same fundamental principles of flight. Likewise, in spite of variations, all successful models of psychoeducation with troubled children must address the same fundamental needs of children. We have sought to identify these common principles that transcend successful work with children regardless of setting or theoretical model.

In our book Reclaiming Youth at Risk (Brendtro, Brokenleg, \& Van Bockern, 1990), we proposed a unifying theme for the education and treatment of troubled children. Dr. Brokenleg, a Lakota Sioux psychologist, introduced us to sophisticated Native American child-rearing systems that created courageous, respectful children without the use of harsh punishments. We integrated this Native wisdom with the practice wisdom of great European pioneers in work with troubled youth. A note about each of these traditions will serve as an introduction to our model.

Psychologists Rogoff and Morelli (1989) contended that, to fully understand child development, one must break free of cultural biases and explore other cultural models. Centuries before European and American reformers would challenge Western patriarchal models of obedience, Native American tribes of North America had developed elaborate democratic institutions, governance systems, and models of education. These "primitive" peoples actually were far more advanced than the conquering Europeans in their understanding of child and youth development. When Europeans settled this new 
land, however, they imposed their obedience training system on Indian children, who were placed forcibly in militaristic boarding schools.

Martin Brokenleg's father was captured by the boarding school staff, who traveled the reservation each fall to harvest the next crop of first-graders. Now, several generations of Indian youth have been parented artificially in this environment, where they were beaten if they spoke their native language. Our research sought to reclaim traditional Native empowerment philosophies for use in developing contemporary approaches to youth at risk.

We also were intrigued to find great similarity between Native concepts of education and ideas expressed by Western educational reformers who challenged traditional European concepts of obedience training. These youth work pioneers worked at a time when democracy was replacing dictatorship in many nations. Attacking traditional authoritarian pedagogy, they included:

Maria Montessori, Italy's first female physician, who created schools for disadvantaged youth and wrote passionately about the need to build inner discipline.

$\square$ Janusz Korczak, Polish social pedagogue, who proclaimed the child's right to respect and created a national children's newspaper so the voices of children might be heard.

John Dewey, American pioneer of progressive education, who saw schools as miniature democratic communities of students and teachers working to pose and solve problems.

$\square$ Anton Makarenko, who after the Russian Revolution brought street delinquents into self-governing colonies where youth took turns as leaders of youth councils.

Now the wisdom of these early pioneers is being validated by modern psychological researchers.

\section{THE CIRCLE OF COURAGE}

Early European anthropologists described Native American children as radiantly happy, courageous, and highly respectful, noting that their elders never subjected them to harsh punishment. The professional literature, however, shows little understanding of how tribal cultures could rear children with prosocial values and positive self-esteem. Long before the term "self-esteem" was coined, European youth work pioneers used a similar concept, which they called "discouragement." The obvious solution to discouragement is to help children develop courage. As we discovered, building courageous children was a central focus of Native American tribal cultures. Our modern "civilization," in contrast, produces millions of children of discouragement. How might we go about rearing courageous and respectful children?

In his definitive work, The Antecedents of Self-Esteem, Stanley Coopersmith (1967) concluded that childhood selfesteem is based on significance, competence, power, and virtue. Traditional Native child-care philosophy addresses each of these dimensions:

1. Significance is nurtured in an environment in which every child is treated as a "relative" and is surrounded by love and affection. This fosters a sense of belonging.

2. Competence is enhanced by nurturing each child's success and by celebrating the success of others. This provides all children abundant opportunities for mastery.

3. Power is fostered by practicing guidance without coercion. Even the youngest children learn to make wise decisions and thus demonstrate responsible independence.

4. The highest virtue is to be unselfish and courageously give of oneself to others. Children reared in altruistic environments learn to live in a spirit of generosity.

Lakota artist George Bluebird portrayed these concepts in a drawing of a medicine wheel called the "circle of courage," featured in Figure 1.

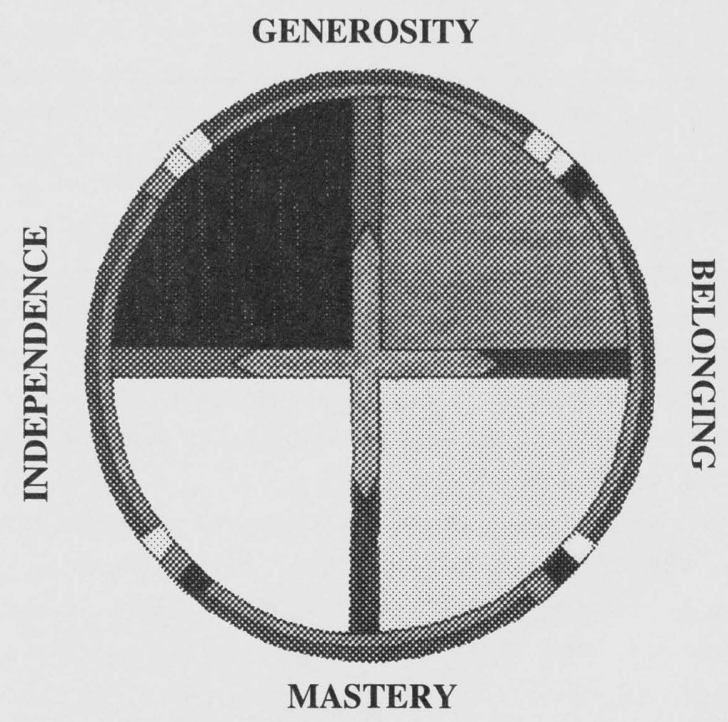

FIGURE 1 Circle of Courage 
At first glance, the foregoing principles hardly seem debatable. They fit with humanistic values, psychology, and our own experience. After all, who would advocate the opposite of these concepts-alienation, failure, helplessness, and egotistic selfishness? Further, convincing youth themselves that these are important values is not difficult. Young people want to belong, succeed, have power over their lives, and be needed in the world. Once these values are given primacy in our programs, their revolutionary quality becomes apparent.

Whereas most of our traditional systems have been anchored in adult dominance, the Circle of Courage is a youth empowerment model. Table 1 shows how Native empowerment values mirror the foundations of self-esteem identified by Coopersmith (1967) and challenge the values of the dominant culture.

\begin{tabular}{lcc}
\hline & TABLE 1 & \\
& $\begin{array}{c}\text { Empowerment Versus } \\
\text { Patriarchal Values }\end{array}$ & \\
$\begin{array}{l}\text { Foundations } \\
\text { of Self-Esteem }\end{array}$ & $\begin{array}{c}\text { Native American } \\
\text { Empowerment } \\
\text { Values }\end{array}$ & $\begin{array}{c}\text { Western } \\
\text { Patriarchal } \\
\text { Values }\end{array}$ \\
$\begin{array}{l}\text { Significance } \\
\text { Competence } \\
\text { Power }\end{array}$ & Belonging & Individualism \\
Virtue & Mastery & Winning \\
& Independence & Dominance \\
& Generosity & Affluence \\
\hline
\end{tabular}

Patriarchal values and the developmental needs of children are strikingly disharmonious.

1. Instead of belonging, the hyperindividualism of Western society breeds an "ecology of alienation" (Bronfenbrenner, 1986).

2. In the place of mastery, traditional schools play a competitive zero-sum game in which enthroning "winners" ensures abundant losers.

3. When one's need for power is expressed by dominating others, all who are subjugated are disempowered.

4. A culture that equates worth with wealth provides its young a sanction for selfishness.

Successful programs for at-risk youth embody a unifying theme of values grounded in the holistic needs of children. Wozner (1985) defined the key difference among educational environments as whether they are "reclaiming" or "nonreclaiming." Reclaiming schools are organized to meet the needs both of the young person and of society. Nonreclaiming schools operate to perpetuate the system. The distinction is whether one is teaching students or tending school.

\section{BLUEPRINT FOR A NONRECLAIMING SCHOOL}

These abstractions can be operationalized by examining some attitudes and practices of nonreclaiming schools. Next, with some hyperbole, we offer a compilation of comments we have heard in various schools.

\section{Anti-Belonging}

Greet newcomers with "report to the office" warning signs. Orient new students and their probably irresponsible parents by making them sign the discipline policy manual. Emphasize that the automatic response to "serious" behavior is exclusion in its many forms including in-school suspension (ISS), out-of-school suspension (OSS), or after school and Saturday (ASS) detention. If students quit, call them "dropouts" (pejorative). Be very businesslike lest you get entangled in "unprofessional" relationships. If kids don't respond, ship them to segregated "alternative" and special education programs to "get them out of our classrooms."

Teachers should not have to wet-nurse students, so get rid of that values clarification crap we are supposed to handle in homerooms. Put troublemaking special ed students, who can't be expelled, on homebound. [Authors' note: $40 \%$ of all students on homebound instruction are those with emotional and behavioral problems.] Make schools as large as possible to build better bands and ball teams. Ring bells every 50 minutes to mix 2,000 kids in narrow hallways. If they become hard to manage, hire more security guards so teachers are free to "teach."

\section{Anti-Mastery}

Organize instruction tightly around separate specialized subjects. Switch to a different group of students each period. You won't know them well, but at least one kid can't ruin your whole day. If students say they are having fun in a class, or if a teacher takes field trips, spread word in the lounge that no learning is going on. Make them work by themselves so they don't copy one another, follow a tight schedule, and have the shortest possible breaks between periods. Fill the 
policy manual with get-tough rules such as, "Students who skip school will be suspended" and "in-school suspension days will be counted as unexcused absences" and "students with 12 unexcused absences will fail the semester."

Emphasize competition with tough grading systems, tracking, and reduced expectations for difficult students. In all "real" classes make all students listen to professor-like lectures that are brain-antagonistic even in the university. Of course we don't mean those "popular" shop, art, and PE classes, because they are activity courses, not real education. If they don't hate it, they won't learn anything. What's all the fuss about outcome-based education? Let's stick to what has worked in the past. Use only the textbook and the "approved" curriculum. Maybe we need some more trophies for the top "winners" in sports and studies.

\section{Anti-Independence}

Impose systemwide discipline policies so we know who really runs this place. Give students a token student-government game to play so they won't challenge our control of really important issues. Make examples of troublemakers by announcing detention lists on the intercom. One thing we don't want is violence, so come down hard on bullies and let them know who's boss so they learn not to pick on others. Assume that if students engage in a spirited discussion about some current event, they are dodging real learning. Pace the room to keep on top of the class. Keep students anchored in their desks. Impose rules by fiat, put names on the board, and have surprise locker searches to keep them off-guard.

Use computers to schedule students because they probably just want to choose classes with their friends. Keep students in submissive roles so they learn to "respect" authority. (Years later the only teachers they will remember are the ones who don't take any crap.) Limit student choice of curriculum, because they aren't mature enough to make those decisions. I think it's time for another of those assertive discipline seminars. I felt so good after the last one, being reassured that this was my class and I was in charge.

\section{Anti-Generosity}

We have to do something to derail this foolish proposal that all students participate in volunteer service learning activities. This only steals time from real learning. Sure, maybe students need to feel needed, but if they want to be bleeding-heart social workers, let them do this on their own time. We have to do something about this cooperative learning movement. It's just a way of letting smart kids do the work for slow ones. Stop cross-age tutoring, because the older youth may take advantage of the younger ones.

And the notion of peer counselors really turns me off. Can you imagine what they would tell each other? Let them bring their problems to a trained guidance counselor. We shouldn't get into controversial social issues in school or teach values, except for the flag and patriotism. We have enough to do in the cognitive domain, so leave affective issues to parents. Also, put a stop to this multiculturalism in curriculum. Immigrant children should become American just as we had to. Today's kids will not produce unless you give them some reward or payoff, but, hey, that's the American system.

Although these comments may not be typical of most schools, a war undoubtedly is going on between tradition and reform in contemporary education. We believe, however, that conflict is the predictable reaction to the real changes sweeping education, and today's reform will be the mode of the future. The empowerment movement in schools must be seen as part of a broader cultural paradigm shift that is unsettling the established power relationships in Western culture.

Many traditionally powerless groups (e.g., women, people of color, ethnic minorities, and now children) are achieving fuller participation in an increasingly democratic world. A prominent example is the recent $\mathrm{U}$. N. document on the rights of children, which has gained the status of international law. This shift to empowerment is a grassroots democracy movement that will impact all social institutions, including the school.

\section{MENDING BROKEN CIRCLES}

Only as we abandon our preoccupation with the control of deviance can we nurture the unmet developmental needs that drive most problem behavior. A growing research base shows that successful psychoeducational programs must nurture belonging, mastery, independence, and generosity in troubled children. Of course, other underlying physical and safety needs exist, but from the perspective of psychosocial development, these are four anchor points.

Belonging, mastery, independence, and generosity define social and mental health. As such, these are universal needs for all children and critical unmet needs for damaged children. Many students come to school already having experienced this 
"circle of courage" in their lives. Many others, however, come to us discouraged, with long histories of unmet needs.

Instead of belonging, they are guarded, untrusting, hostile, withdrawn; or they seek attention through compensatory attachments.

$\square$ In place of mastery, they have encountered perpetual failure leading to frustration, fear of failure, and a sense of futility.

$\square$ Not having learned independence, they feel like helpless pawns, are easily misled, or seek pseudopower by bullying or defiance.

$\square$ Without a spirit of generosity, they are inconsiderate of others, self-indulgent, and devoid of real purpose for living.

Recently one of our graduate students surveyed high school students and asked them to "grade their schools" according to the criteria of belonging, mastery, independence, and generosity (Odney \& Brendtro, 1992). Some of their comments will be used to introduce the following sections. After hearing their voices, we will identify a range of intervention techniques for mending broken circles of courage.

\section{Fostering Belonging}

Some of the teachers think they are too cool to talk to us. If you're walking down the hall, the teachers will put their heads down and look at the floor and keep walking.-Helen

Pioneer Native American educator and anthropologist Ella Deloria described the central value of belonging in traditional Indian culture in these simple words: "Be related, somehow, to everyone you know." Treating others as kin forged powerful social bonds of community that drew all into the circle of relatives. From the earliest days of life, all children experienced a network of nurturance, wherein every older member in the tribe felt responsible for their well-being.

Theologian Martin Marty of the University of Chicago observed that throughout history the tribe, rather than the nuclear family, ultimately ensured survival of a culture. When parents faltered in their responsibility, the tribe always was there to nourish the new generation. The problem today is that we have lost our tribes. The school is the only institution beyond the family that provides ongoing relationships with all of our young. Schools could become the new tribes to support and nurture children at risk.
Early educational pioneers saw positive human attachments as the sine qua non of effective teaching. Johann Pestalozzi declared that love, not teaching, was the essence of education. In his classic book, Wayward Youth, Austrian August Aichorn (1935) argued that relationship was the heart of the reeducation process. His ethic was that affection rather than punishment must be dispensed to difficult youth because this is their primary unmet need. As educational literature became more "professional," however, relationship building was ignored temporarily. Now the importance of human attachment is the focus of a revival of interest.

Research shows that the quality of human relationships in schools and youth service programs may be more influential than the specific techniques or interventions employed (Brophy, 1986). Teachers with widely divergent instructional styles can be successful if they develop positive classroom climates. Building successful relationships, however, takes time and effort.

The late eminent psychiatrist Karl Menninger often noted that many of today's youth do not experience a sense of belonging at home. When they come to school and behave in unacceptable ways, they get another unbelonging message: "People who act like that don't belong here." Some youth quit trying to build human bonds and begin to protect themselves with a guarded, suspicious, withdrawn manner. Others do not give up seeking attention, recognition, and significance. Instead they pursue "artificial belongings" in gangs, cults, or sexual promiscuity.

Hostile or withdrawn youth often are signaling to adults that they have learned by experience to expect rejection, and untrained people almost invariably give them what they are used to receiving. Many ways of reaching out to these unloved and sometimes unlovable children are possible if adults can overcome the fight or flight reactions that come so naturally. Following are strategies for meeting the needs for attachment and belonging, which have developed in various theoretical traditions.

1. Psychodynamic programs long have posited that strong, trusting relationships between troubled youth and adults were prerequisites to effective reeducation. Youth work pioneer August Aichorn concluded that love is the primary unmet need of many troubled children. Morse emphasized the importance of "differential acceptance," in which we accept the child but not the behavior. To accurately decode "testing" behaviors also is important. 
Many troubled children initially provoke well meaning adults to see if they will become hostile.

2. Behavioral research by Phillips and colleagues (1973) reported a failure to replicate their achievement place model when positive staff-student relationships were missing. Now called the teaching family model, relationship building components are central to this approach. The staff is trained to begin all corrective teaching interactions with a positive or empathy statement.

3. Sociological models use peer relationships as the foundation for treatment. This method is powerful particularly with youth who initially are inclined to trust peers more than adults. Peer concern rather than peer pressure is the basis for program success. Adults must model caring relationships and monitor confrontations carefully so students don't become targets of counteraggression (Brendtro \& Ness, 1982).

4. Ecological models developed by Hobbs (1982) presume that the disturbed youth begins with a belief that most adults cannot be trusted. Only the people who can break down this barrier of trust can become predictable sources of support, affection, and learning. In Re-ED programs, "trust ... is the glue that holds teaching and learning together, the beginning point of reeducation."

The emphasis on fostering attachments is also prominent in the middle school movement. Typically, schedules are designed so frequent and sustained contact between students and teachers is possible. Maeroff (1990) described one program in which a small team of four to five adults, including teachers, administrators, and counselors, serves 45 students. Each adult meets twice daily with a smaller advisory group of 8-10 students. In another middle school teachers greet their students as the buses arrive. Bells are eliminated, teamteaching is used, four award assemblies are held throughout the year, and F's have been changed to U's (Raebuck, 1990).

The celebration of belonging to a caring community is a central theme of effective schools. O'Gorman, a Catholic high school in Sioux Falls, South Dakota, invites new freshman students to a "unity weekend" retreat over the Labor Day holiday. Some of the 90 trained senior volunteers welcome the new students, helping them carry sleeping bags and luggage into the school and providing leadership for the weekend activities. Students from outlying communities who have no preexisting peer relationships at this school receive a special invitation to a picnic and water-slide party hosted by a school counselor and the natural peer helper organization. Here, too, a strong advising system anchors each student in a close relationship with a small cadre of peers and a teacher-counselor.

Teachers in American schools traditionally have been attached to grade levels or subjects, not to cohorts of students. In contrast, Norwegian elementary school teachers often progress through the grades, remaining with one group of students for several years. In like manner, Holweide, a comprehensive secondary school in Cologne, West Germany, assigns teachers to teams of six or eight, which follow the same 120 students over the course of 6 years. In this structure the beginning and year-end rituals are eliminated, freeing more time for instruction. These teachers come to know their students in ways that tests never can approach (Shanker, 1990).

Positive attachments between adults and youth are the foundation of effective education. These individual bonds, however, must be part of a synergistic network of relationships that permeate the school culture. These include positive peer relationships among students, cooperative teamwork relationships among school staff, and genuine partnerships with parents. Administrators also must see their roles as co-workers in support of their staff, not as superiors trying to dominate. In the final analysis, only adults who are themselves empowered will be free to build empowering relationships with youth.

\section{Fostering Mastery}

I was walking down the hall and said "hi" to Mr. Nilson. He looked at me and said, "Oh, you're still here. You haven't dropped out yet, huh?" I know people have this in their head and think of me as being less than them. I would like to put Mr. Nilson in the situation I've had in my life, and I'll bet any amount of money he'd fold his cards. - Lincoln

In traditional Native American culture, children were taught to celebrate the achievement of others, and a person who received honor accepted this without arrogance. Someone more skilled than oneself was seen as a model for learning, not as an adversary. The striving was for personal mastery, not to become superior to one's opponent. Recognizing that all must be nourished in competency, success became a possession of the many, not of the privileged few.

Maria Montessori, Italy's first female physician, decried the obedience tradition of schooling in which children sit silently 
in rows like "beautiful butterflies pinned to their desks." She tried to revolutionize learning with the belief that curiosity and the desire to learn come naturally to children.

The desire to master and achieve is seen in all cultures from childhood onward, a phenomenon that Harvard psychologist Robert White called "competence motivation." People explore, acquire language, construct things, and attempt to cope with their environments. It is a mark of humanness that children and adults alike desire to do things well and, in so doing, gain the joy of achievement.

Tragically, though, something often happens to the child's quest for learning in school, the very place where mastery is supposed to be nourished and expanded. Schooling in the traditional setting often fragments learning into subject areas, substitutes control for the natural desire to learn, co-opts naturally active children for hours in assembly line classes, ignores both individual and cultural differences, and is structured on competitive learning (Overly, 1979).

Children who lack skills in social or academic realms often appear resistant to learning. They withdraw from challenge and risk, avoiding most what they understand least. As Mary MacCracken (1981) said in her book City Kid, "When you have failed often and painfully enough, you will do almost anything to avoid having to try again" (p. 152).

Each of the treatment models has sophisticated strategies for breaking patterns of failure and futility. All address the crucial task of teaching social skills. Sometimes this is highly structured, as in direct instruction using formal curricula of social skills. In some models the demonstrated problem itself becomes the curriculum for teaching new ways of coping, as in life space interviews or peer counseling groups. Instead of communicating "I don't want to see any problems," educators and therapists are learning to use naturally occurring incidents as the basis for instruction. A sampling of promising methods for helping children achieve mastery and social competence follows.

1. Psychodynamic methods encourage creativity and selfexpression in the curriculum to create a sense of mastery. Art, drama, music and poetry, literature-all can help youth connect with their feelings and surmount their problems. If problems cannot be eliminated immediately, they should be recast as learning opportunities. In the life space interview (LSI), real-world problems are grist for learning more adaptive ways of thinking, feeling, and acting. Instead of withdrawing from youth in times of crisis, the staff sees this as a unique window of opportunity for teaching coping skills.

2. Behavioral programs, of course, are grounded in learning theory. Among the most useful contributions are systematic social skills instruction to develop social competence and teach adaptive skills. These skills can be as diverse as asking for help and making friends. Students entering a teaching family program are taught up front how to accept criticism, using role playing and other realistic methods. Even before their first encounter with an adult, they are being given new coping strategies. Cognitive behavioral techniques are employed to replace irrational thinking or destructive self-talk with more accurate and adaptive thinking.

3. Sociological models train youth to assume problem-solving roles. The treatment group provides feedback about hurtful or inconsiderate behavior of members and encourages positive alternatives. For example, easily angered youth are taught to understand and disengage from the put-down process, thereby inoculating themselves from the negative behavior of others. Of course, positive groups also foster positive attitudes toward school and teachers.

We recall a substitute teacher who most reluctantly accepted her first assignment to a class of delinquent youth in a peer treatment program. She was dumbfounded when the first discipline problem of the day was solved instantly by peers with a chorus of "leave the teacher alone so she can teach!"

4. Ecological Re-ED programs assume that competence and intelligence can be taught. Academic success itself is seen as a powerful therapy. By helping youth be good at something, especially schoolwork, one impacts a person's selfworth and motivation. Students also need opportunities for problem solving in interpersonal relationships in which they display "conspicuous ineptitude." This model also uses extensive adventure and outdoor education activities to reach students who don't respond to typical school structures.

Traditional educational approaches were developed centuries before any scientific understanding of the human brain. With increased knowledge of how the human brain functions, we now are able to restructure schooling so it is "brain friendly." Leslie Hart (1983), who has synthesized brain research related to education, suggests that the brain is 
designed to detect patterns and works best in nonthreatening, active, and social settings.

Writing in 1909 in The Spirit of Youth and the City Streets, Jane Addams observed that many of the difficulties of youth are related to the reality that they are highly spirited and adventurous. A distinctive feature of much youthful delinquency is the celebration of prowess. These youth are not motivated by the humdrum routine of most schools. Their search for fun and adventure often leads to excitement and kicks through risk-seeking behavior.

Wilderness education programs build on this spirit of adventure. When struggling against the elements of nature, even the most resistant youth has no need to defy the law of natural consequences (Bacon \& Kimball, 1989). The Eckerd Wilderness Educational System operates a network of programs for youth at risk across the eastern United States. While totally abandoning the traditional classroom structure, its staff is able to make formidable academic and social gains with previously nonachieving youth.

\section{Fostering Independence}

This is probably the biggest part of school that I don't like. All through school, kids are herded around like sheep and are left with almost nothing to decide upon.-Travis

Traditional Native culture placed a high value on individual freedom. In contrast to "obedience" models of discipline, Native education was designed to build "respect" by teaching inner discipline. Children were encouraged to make decisions, solve problems, and show personal responsibility. Adults modeled, taught values, and provided feedback and guidance, but children were given abundant opportunities to make choices without coercion.

Horace Mann once declared schooling in a democracy to be "an apprenticeship in responsibility." Early in the century Janusz Korczak of Poland founded a system of student selfgovernance in his orphanage for Warsaw street children. "Fifty years from now, every school in a democracy will have student self governance," he declared. But America continues to be uniquely out of step with many other nations that have implemented the principles of "democracy in education" for which American John Dewey is famous. We remain tethered to the obedience model, causing anthropologist Ruth Benedict to exclaim that our culture systematically deprives young people of the opportunity for responsibility and then complains about their irresponsibility.
A 6,000-year-old Egyptian stone bears the inscription: "Our earth is degenerate. Children no longer obey their parents." Similar calls are heard today, and those who think we have been too permissive could be expected to object to the notion of giving power to youth. The choice, however, is not between demanding obedience or total permissiveness. As Mary Wood says, adults need to continue to be in controlbut of the learning environment rather than of the children. Put another way, we must make demands; however, we need to demand responsibility instead of obedience. Even when we intervene in behavior, the tone can be, "Why must adults handle this problem when you are mature enough to handle it yourselves?"

Youth deprived of power will get it somehow, often in a delinquent underground as they bully the weakest in their midst and sabotage our adult-dominated programs. Fortunately, all treatment models are recognizing the need to listen to the voices of youth, as seen in these strategies for teaching independence and self-control.

1. Psychodynamic approaches assume that many aggressive children lack sufficient self-management of emotions and behavior. The goal is to develop "controls from within." Redl and Wineman (1957) offered detailed behavior management strategies for providing external controls temporarily while at the same time using "clinical exploitation of life events" to teach the youth self-responsibility. Wood and Long (1991) outlined counseling methods to help children "master the existential crisis" of gaining responsible independence from adults.

2. Behavioral approaches to aggression also teach youth selfmanagement skills for dealing with anger. These include recognizing "triggers" and "cues" for anger arousal, using self-administered "reminders" and "reducers" to lessen anger, and self-evaluation and reinforcement (Goldstein \& Glick, 1987). Boys Town uses procedures whereby youth help decide the rules by which they will live in teaching family homes. Cognitive behavior theorist Meichenbaum (1993) now emphasizes that individuals construct their own personal realities, and the therapist's task is to help them take charge of reconstructing more positive personal outlooks to manage life stress.

3. Sociological models of group treatment reject the "patient" role and empower students to become agents of their own healing. Individuals are held accountable for behavior, and excuses are turned back to the individual in 
a verbal technique called the "reversal of responsibility." For example, if a student rationalizes a fight, saying, "Well, he said things about my mother that were lies!" the group may respond, "Well, that's his problem, so why did you make his garbage yours?" By helping others with similar problems, youth develop a sense of control over their own destiny.

4. Ecological programs also use self-governing groups to implement behavioral programming (Lewis \& Lewis, 1989). Any member can call together a problem-solving group. These groups often are led by youth. The group helps the member learn new strategies for avoiding the problem, thereby encouraging responsible behavior in all members. Rhodes (1992), a co-founder of the Re-ED model, has developed a life-impact curriculum that empowers children's thinking so they can "reconstruct their own reality."

The German youth work pioneer Otto Zirker once observed that when surrounded by walls, young people make wall climbing a sport. Faced with authoritarian structures, youth willingly enter into the counter-control game. Adults who struggle to manage behavior by power assertion believe they are engineering an orderly environment. The reality is more often a submerged negative subculture marked by chaos and disorganization (Wasmund, 1988).

In their study of effective alternative schools, Expelled to a Friendlier Place, Gold and Mann (1984) challenged the common practice of employing highly developed formal codes of conduct to manage behavior. Although these rule books make some adults feel secure, they are likely to be ignored or outmaneuvered if they are not owned by front-line staff and youth. Effective alternative schools are able to adapt flexibly to the needs of youth rather than make every decision "by the book." The emphasis shifts from pursuing rule violators to teaching values that foster inner control. Such is the case at the Thomas Harrington School in Harrisonburg, Virginia, where one rule applies equally to all students and staff: Respect people, respect property (Raebuck, 1990).

Independence for many youth is thwarted by inflexible and uncompromising structures. At the Jefferson County High School in Louisville, Kentucky, success with at-risk youth comes from flexible schedules (school is open from 8 A.M. to 9:30 P.M., 12 months a year), promise of success, treating students with respect, and awarding a regular high school diploma. The director of this alternative school, Buell Snyder, said, "I hire only teachers who agree to treat students with respect at all times, and I discard those who, despite their good intentions, infantilize or ridicule students" (Gross, 1990).

\section{Fostering Generosity}

I would have liked to tutor something or been a peer counselor. I could have helped someone and benefited from it myself if I had been given the chance to participate.-Sondra

A central goal in Native American child rearing is to teach the importance of being generous and unselfish. Children were instructed that human relationships were more important than physical possessions. Describing practices a century ago, Indian writer Charles Eastman tells of his grandmother teaching him to give away what he cherished the most-his puppy - so he would become strong and courageous.

Pioneering German educator Kurt Hahn once observed that all young people desperately need some sense of purpose for their lives. Youth in modern society, however, do not have roles in which they can serve, and thus they suffer from the "misery of unimportance." Hahn advocated volunteer activities that tap the need of every youth to have some "grande passion." During the Hitler years he went to England, where he developed the basis of the Outward Bound movements.

Rousseau, Pestalozzi, Korczak, and many others also wrote of the importance of teaching youth the values of compassion and service to others. A century ago, William James noted that war always has fulfilled young men's need to be valuable to their community. He proposed a "moral equivalent to war" by involving youth in volunteer civic service. Although we seem to have lost sight of these basic truths for a time, there is now a healthy revival of the concept that we must offer opportunities to develop altruism, empathy, and generosity in modern youth (Kohn, 1990).

The following discussion highlights the increasing emphasis being placed on developing prosocial values and behavior as an antidote to hedonistic, antisocial lifestyles that characterize many modern youth.

1. Redl's psychodynamic model departs from traditional Freudian views that children experience too much guilt. Today, many youth seem not to have acquired the most basic sense of human concern. They suffer from too little guilt, and they can hurt or exploit others with impunity. 
Treatment for these children might involve "guiltsqueeze" life space interviews to foster empathy with victims, or "massaging numb values" to foster internalization of caring values.

2. Behavioral research suggests that teaching techniques to manage anger is not enough. Youth will choose prosocial alternatives only if they can move beyond egocentric moral reasoning. Thus, cognitive moral education is part of Goldstein's aggression replacement training. Everson (1994), from the Boys Town program, advocates teaching social skills as a way of fostering moral development. The goal is to create moral dilemmas in once self-centered youth. Now empowered with prosocial skills, youth have new options to act in caring ways.

3. Sociological group treatment models seek to "make caring fashionable" and to make youth uncomfortable with selfish, hurting behavior and thinking patterns. Positive peer culture programs teach youth to show concern by helping group members and then give them abundant opportunities to generalize helping behavior through service learning. For example, delinquent youth at Starr Commonwealth regularly "adopt" residents of nursing homes as grandparents, and they serve as basketball coaches to younger community children.

4. Ecological programs address the children and families who are alienated from community bonds. Re-ED involves students in community service in a variety of ways including helping the elderly, operating a "roadblock" to solicit funds for a hospital, and distributing food and toys to needy families.

Every level of education has seen a revival of interest in volunteer service learning as an antidote to the narcissism and irresponsibility of modern lifestyles. All over the country in alternative and some traditional settings, examples of service learning can be found. At Chadwick School in Los Angeles, privileged students run a soup kitchen, help the mentally ill put on plays, work with disturbed children, and campaign for environmental protection. At Harlem's Rice High School in New York, students work with the sick and needy. In Connecticut students serve as the professional rescue squad for a semirural area. In all of these programs, young people's abilities to participate and help are valued (Lewis, 1990).

For 6 to 8 weeks in Shoreham-Wading River, students spend a double period, twice a week, in some community ser- vice activity. Students, for example, may work with elderly people or those with handicaps (Maeroff, 1990). Students in Petaluma, California, worked hard to clean up the endangered Adobe Creek. They hauled out 20 truckloads of junk, including washing machines, sofas, two beds, and 36 old tires. They planted willow trees. Now the group is trying to raise $\$ 200,000$ for a fish hatchery. At least 25 ex-students are studying natural resources and wildlife at Humboldt State University in northern California. Three others are majoring in environmental law at other schools (Sims, 1990).

Service learning opens unusual programming possibilities with troubled children and youth who heretofore have seen themselves as "damaged goods." As they reach out to help others, they create their own proof of worthiness (Brendtro \& Nicholau, 1985). Diane Hedin (1989) summarized various research studies supporting the positive results of volunteer service. These include increased responsibility, self-esteem, moral development, and commitment to democratic values.

\section{PUTTING IT ALL TOGETHER: THE MICHIGAN STUDY}

Our thesis has been that reclaiming programs must address the critical variables of belonging, mastery, independence, and generosity. We close this article by highlighting a recent study of more than 300 delinquent youth in Michigan correctional facilities (Gold \& Osgood, 1992). The programs encompassed two state and two private treatment centers using positive peer culture (PPC) treatment methodology.

The Michigan researchers gathered exhaustive data from records, referral agencies, staff, students, and caregivers. They observed each youth from arrival until 6 months' follow-up after release. The population consisted of boys, generally 15 or 16 years old, who had been arrested from one to 20 times. The typical student was remarkably unsuccessful in school, with average academic achievement 4.2 grade levels below expectation. A third had not even attended in the period before placement. These youth are representative of those served currently by North American juvenile corrections programs.

The youth lived in 45 separate self-contained treatment/ classroom groups, each with its own interdisciplinary staff team. This enabled researchers to study the impact of these different treatment environments. Thus, though all programs used peer group treatment, they differed on variables such as 
the amount of autonomy given to youth and the closeness of staff and youth relationships. Variations in the group culture were related to success in the program and in the community after release.

Gold and Osgood reviewed prior research showing that homogeneous settings for aggressive youth typically spawn strongly negative youth countercultures. Instead of cooperating with treatment goals, students resist adult control, develop a code of silence against informing on one another, go underground to circumvent institutional rules, and use physical coercion to maintain a peer subculture committed to delinquent values and behavior. An ongoing debate in the research literature is considering why these negative subcultures form. Two competing explanations have been proposed:

1. Negative youth traits: Delinquent youth "import" into the reeducation setting their dysfunctional character traits. This is a collective example of the "bad apple" notion.

2. Negative institutional milieu: Depriving environments create aggressive countercultures. Harsh, coercive settings strip youth of autonomy and decision making, thus fostering rebellion.

Contrary to what might have been expected, Gold and Osgood found that delinquents in the Michigan settings regularly viewed their environments as safe and supportive. Although full consideration of their exhaustive study is beyond the scope of our current discussion, we highlight their findings related to the principles of belonging, mastery, independence, and generosity.

$\square$ Belonging: The more troubled and beset youth are, the more they need close personal attachments to reconstruct their lives. Adults who do not form these bonds distance themselves from delinquent youth and thereby diminish their ability to influence them.

$\square$ Mastery: Delinquent behavior often is provoked by scholastic failure. Teachers in successful school programs give students "uncommonly warm emotional support" and prevent them from failing. Youth who become interested in school and make achievement gains have better subsequent community adjustment.

$\square$ Independence: Involving delinquent youth in decision making, even in highly secure settings, fosters the turnaround to prosocial behavior. Adult domination and autho- ritarian control feeds negative peer subcultures, which sabotage treatment goals.

$\square$ Generosity: High value is placed on caring in peer-helping programs, and a key measure of progress is showing concern for other group members. Students who adopt prosocial norms have more positive experiences during treatment and gain access to more prosocial reference groups after leaving the program.

The Michigan research also shows that the "treatment versus custody" debate is bogus, as concern and control are both essential. Successful programs find ways to address developmental needs of youth as well as societal needs to stop destructive behavior. This requires adults who are authoritative but not authoritarian. These data contradict the currently popular boot-camp notion that the harsher the institutional experience, the greater is the deterrent effect. In reality, troubled youth need safe, positive environments where they can form corrective social bonds with caring adults and peers.

\section{REFERENCES}

Addams, J. (1909). The spirit of youth and the city streets. New York: Macmillan.

Aichorn, A. (1935). Wayward youth. New York: Viking Press.

Bacon, S. B., \& Kimball, R. (1989). The wilderness challenge model. In R. Lyman, S. Prentice-Dunn, \& S. Gabel (Eds.), Residential and inpatient treatment of children and adolescents. New York: Plenum Press.

Brendtro, L., Brokenleg, M., \& Van Bockern, S. (1990). Reclaiming youth at risk: Our hope for the future. Bloomington, IN: National Educational Services.

Brendtro, L., \& Ness, A. (1982). Perspectives on peer group treatment: The use and abuse of guided group interaction/positive peer culture. Children \& Youth Services Review, 4(4), 307-324.

Brendtro, L., \& Ness, A. (1983). Re-educating troubled youth: Environments for teaching and treatment. New York: Aldine du Gruyter.

Brendtro, L., \& Nicholau, A. (1985). Service learning with behaviorally disordered students. [Monograph on severe behavior disorders of children and youth]. Council for Children with Behavior Disorders, Arizona State University, Tempe.

Brendtro, L., \& Wasmund, W. (1989). The peer culture model. In R. Lyman, S. Prentice-Dunn, \& S. Gabel (Eds.), Residential and inpatient treatment of children and adolescents. New York: Plenum Press.

Bronfenbrenner, U. (1986). Alienation and the four worlds of childhood. Phi Delta Kappan, 67, 430-436.

Brophy, J. (1986). Teacher influences on student achievement. American Psychologist, 41, 1069-1077.

Cantrell, M. (1992). Guns, gangs and kids. Journal of Emotional \& Behavioral Problems, 1(1), Special issue. 


\section{NEW FOR 1994}

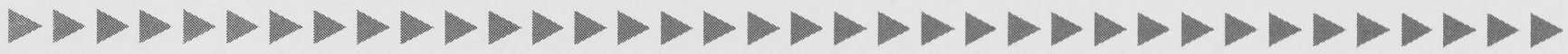

\section{Collaborative Practitioners, Collaborative Schools}

MARLEEN C. PUGACH

University of Wisconsin-Milwaukee

LAWRENCE J. JOHNSON

University of Cincinnati

This new book focuses on teamwork in the schools, showing how school professional and family members can work together to help children learn and adjust to the school environment. It begins with a detailed description of the rationale and framework behind collaboration. Collaboration among school professionals is based on the philosophy that all professionals have something to contribute to the collaborative process, not just the expert consultant. The most important skill in being an effective collaborator is the ability to communicate ideas effectively. You'll find three chapters dealing with communication skills.

Each chapter has a summary with highlights and activities to help your students prepare for using these ideas in their daily teaching.

\section{CONTENTS}

1. Collaboration and the Complex Work of Teaching

2. A New Framework for Thinking About Collaboration

3. Communication: The Foundation of Collaboration

4. Skills to Facilitate Effective Communication

5. Barriers to Effective Communication

6. Working with and Supporting Groups

7. Collaboration as Specific Problem Solving

8. Team Teaching as Collaboration

9. School-University Collaboration

10. School-Family Collaboration

9402 / paperback / ISBN 0-89108-234-4 / \$24.95

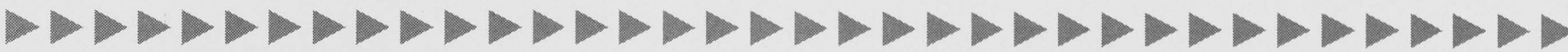

\section{Special Education}

\section{and Student Disability}

Traditional, Emerging, and

Alternative Perspectives

Fourth Edition

\section{EDWARD L. MEYEN and THOMAS M. SKRTIC}

University of Kansas

Previous editions titled

Exceptional Children and Youth

Now, for the first time, a new introductory book written for the serious professional.

Part one of this new fourth edition provides a comprehensive coverage of all exceptionalities with discussions on inclusion, diversity, new legislation, and a wide range of critical issues and concerns for special education
Part two presents alternative perspectives that challenge the traditional practices and shows an entirely new way of understanding special education.

You will find services, programs, delivery systems, assessment, family, and much, much more in this new revision. School reform and restructure are examined with their implications for special education in mind.

\section{SPECIAL FEATURES}

- More challenging and thought provoking than traditional introductory texts

- Up-to-date and includes the very latest research findings

- Fresh, lucid approach to the changes taking place in the field

- Latest legislation is interwoven throughout the text

9307 / hardback / ISBN 0-89108-231-X / \$47.95

Available August 1994
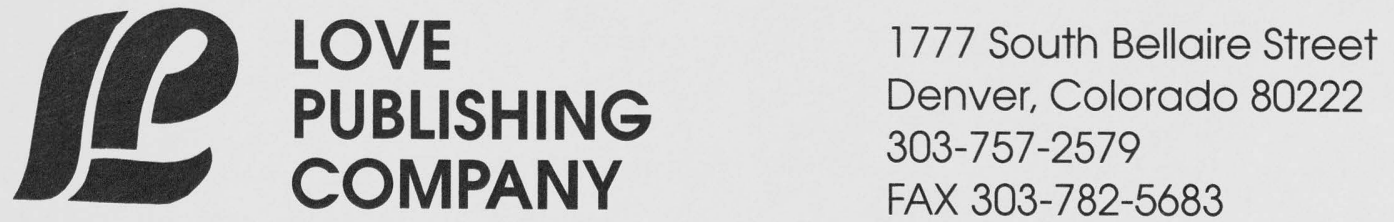

1777 South Bellaire Street

Denver, Colorado 80222

FAX 303-782-5683 
Carducci, D., \& Carducci, J. (1984). The caring classroom. Palo Alto, CA: Bull Publishing.

Coopersmith, S. (1967). The antecedents of self-esteem. San Francisco: W. H. Freeman.

Coughlin, D., \& Shanahan, D. (1991). Boys Town family home program training manual (3rd ed.). Boys Town, NE: Father Flanagan's Boys' Home.

Duke, D., \& Meckel, A. (1984). Teacher's guide to classroom management. New York: Random House.

Empey, L., \& Rabow, J. (1961). The Provo experiment in delinquency rehabilitation. American Sociological Review, 26, 683.

Everson, T. (1994). The spiritual development of youth at risk. Journal of Emotional \& Behavioral Problems, 3(10).

Garner, H. (1982). Positive peer culture programs in schools. In D. Safer (Ed.), School programs for disruptive adolescents. Baltimore: University Park Press.

Gold, M., \& Mann, D. (1984). Expelled to a friendlier place: A study of effective alternative education. Ann Arbor: University of Michigan Press.

Gold, M., \& Osgood, D. W. (1992). Personality and peer influence in juvenile corrections. Westport, CT: Greenwood Press.

Goldstein, A. (1988). The prepare curriculum: Teaching pro-social competence. Champaign, IL: Research Press.

Goldstein, A., \& Glick, B. (1987). Aggression replacement training: A comprehensive intervention for aggressive youth. Champaign, IL: Research Press.

Gross, B. (1990). Here dropouts drop in—and stay! Phi Delta Kappan, $71(8), 625-627$.

Hart, L. A. (1983). Human brain and human learning. New York: Longman.

Hedin, D. (1989). The power of community service. Proceedings of Academy of Political Science, 31(2), 201-213.

Hobbs, N. (1982). The troubled and troubling child. San Francisco: JosseyBass Publishers.

Kern, D., \& Quigley, R. (1994). Developing youth potential [video]. National Association of Peer Group Agencies, Woodland Hills, 4321 Allendale Ave., Duluth, MN 55803.

Kohn, A. (1990). The brighter side of human nature: Altruism and empathy in everyday life. New York: Basic Books.

Lewis, A. (1990). On valuing young people. Phi Delta Kappan, 71(6), $420-421$.

Lewis, W., \& Lewis, B. (1989). The psychoeducational model: Cumberland House after 25 years. In R. Lyman, S. Prentice-Dunn, \& S. Gabel (Eds.), Residential and inpatient treatment of children and adolescents. New York: Plenum Press.

MacCracken, M. (1981). City kid. New York: Signet Books.

Macmillan, D. L., \& Kavale, K. A. (1986). Educational intervention. In H. Quay \& J. S. Werry (Eds.), Psychopathological disorders of childhood. New York: John Wiley \& Sons.
Maeroff, G. (1990). Getting to know a good middle school: Shoreham-Wading River. Phi Delta Kappan, 71(7), 505-511.

Makarenko, A. S. (1956). Werke [Works], (Vol. 5). Berlin: Volk \& Wissen Volkseigener Verlag.

Meichenbaum, D. (1993). Changing conceptions of cognitive behavior modification: Retrospect and prospect. Journal of Consulting \& Clinical Psychology, 62(2), 202-204.

Morse, W. C. (1985). The education and treatment of emotionally impaired children and youth. Syracuse, NY: Syracuse University Press.

Morse, W. C., Cutler, R., \& Fink, A. (1964). Public school classes for emotionally handicapped children. Washington, DC: Council for Exceptional Children.

Odney, J., \& Brendtro, L. (1992). Students grade their schools. Journal of Emotional \& Behavioral Problems, 1(2), 2-9.

Overly, N. (Ed.). (1979). Lifetime learning. Alexandria, VA: Association of Supervision \& Curriculum Development.

Phillips, E., et al. (1973). Achievement place: Behavior shaping works for delinquents. Psychology Today 7(1), 74-80.

Quay, H., \& Werry, J. S. (Eds.). (1988). Psychopathological disorders of childhood. New York: John Wiley \& Sons.

Raebuck, B. (1990). Transformation of a middle school. Educational Leadership, 47(7), 18-21.

Redl, F., \& Wineman, D. (1957). The aggressive child. New York: Free Press. (combined version of two earlier books, Children who hate and Controls from within)

Rhodes, W. C. (1992). Empowering young minds. Journal of Emotional \& Behavioral Problems, 1(2). (special issue on Life-Impact Curriculum)

Rogoff, B., \& Morelli, G. (1989). Perspectives on children's development from cultural psychology. American Psychologist, 44(2), 343-348.

Shanker, A. (1990). The end of the traditional model of schooling and a proposal for using incentives to restructure our public schools. Phi Delta Kappan, 71(5), 345.

Sims, C. (1990). Teens mop up. Outdoor, 5(2), 23-24.

Tierney, J., Dowd, T., \& O'Kane, S. (1993). Empowering aggressive youth to change. Journal of Emotional \& Behavioral Problems, 2(1), 41-45.

Vorrath, H., \& Brendtro, L. (1985). Positive peer culture (2nd ed.). New York: Aldine du Gruyter. (First edition published 1967)

Wasmund, W. (1988). The social climates of peer group and other residential programs. Child \& Youth Care Quarterly, 17, 146-155.

Whittaker, J. (1980). Caring for troubled children. San Francisco: JosseyBass Publishers.

Wood, M., \& Long, N. (1991). Life space intervention: Talking with children and youth in crisis. Austin, TX: PRO-ED.

Wozner, Y. (1985). Institution as community. Child \& Youth Services, 7 , 71-90.

\section{PERMISSIONS AND COPYRIGHT}

All rights are reserved. No part of this publication may be reproduced, photocopied, faxed, stored in a retrieval system, or transmitted, in any form or by any means, electronic, mechanical, recording or otherwise, without the prior written permission of the publisher.

Back issues are available for sale. Reproduction requires permission and payment of fees. It is illegal and a violation of federal copyright law to reproduce this publication without permission. Direct all inquiries to the permissions editor. 